\title{
A Response to Viewpoints on Healthcare Delivery Science Education Among Practicing Physicians in a Rural State [Response to Letter]
}

This article was published in the following Dove Press journal:

Advances in Medical Education and Practice

\author{
Kristin Weeks $\mathbb{D}^{1,2}$ \\ Morgan Swanson (DD ${ }^{1,2}$ \\ Amanda Manorot ${ }^{3}$ \\ Gabriel Conley ${ }^{4,5}$ \\ Joseph Nellis ${ }^{6}$ \\ Mary Charlton ${ }^{2}$ \\ Alan Reed (1D ${ }^{7}$
}

'Medical Scientist Training Program, Carver College of Medicine, University of lowa, lowa City, IA, USA; ${ }^{2}$ Department of Epidemiology, College of Public Health, University of lowa, lowa City, IA, USA;

${ }^{3}$ Department of Obstetrics and

Gynecology, University of Michigan, Ann Arbor, MI, USA; ${ }^{4}$ Medical Training Program, Carver College of Medicine, University of lowa, lowa City, IA, USA;

${ }^{5}$ Department of Business, Tippie College of Business, University of lowa, lowa City, IA, USA; ${ }^{6}$ Department of Surgery, Duke University, Durham, NC, USA;

${ }^{7}$ Department of Surgery, University of lowa Hospitals and Clinics, lowa City, IA, USA
Correspondence: Alan Reed

Department of Surgery, University of lowa Hospitals and Clinics, SE $427 \mathrm{GH}$,

200 Hawkins Drive, lowa City, IA, 52242, USA

Tel + I 319-356-0537

Email alan-reed@uiowa.edu

\section{Dear editor}

We appreciated the letter to the editor from Chandran et al offering their perspectives on the educational commitments required to learn and apply HDSE concepts in practice. In response, we must stress the importance of taking into account the intended learner of our study program. The track we described in our manuscript introduces 12 core topic areas of HDSE and allocates time for the practiced application of these concepts. We acknowledge that this track on its own may be insufficient for physician administrators, who likely need a mastery level of knowledge for their scope of practice. However, we feel that this fundamental training provides an indispensable and beneficial opportunity for established physicians with limited prior didactic HDSE experiences to realize concepts and identify areas to pursue greater depth of knowledge.

Chandran et al acknowledged that the participants in our study were primarily physicians with limited to no prior didactic HDSE experiences. We have conducted a successive quantitative study of the same target population and similarly found most physicians sampled had limited to no prior didactic HDSE experiences. ${ }^{1}$ We have identified a critical and urgent need to focus our attention on investigating physician viewpoints on beginner level training in HDSE.

Chandran et al suggested that physicians are unlikely to appreciate the value of HDSE until they themselves "grasp a thorough understanding of HDSE concepts." Our program's intended goal is to provide a practical and realistic education program to established physicians, who have significant time constraints they must balance with a desire to acquire HDSE. The counterfactual, or alternative pathway, for our study population is likely not a more robust and time-consuming HDSE program, but rather no HDSE program at all. We aim to provide a pathway for physicians practicing for years to decades in the business of medicine to have adequate opportunities to pursue and judge their aptness for introductory HDSE.

Concerns from Chandran et al regarding the potential for information transmission fallacy are well-received. This potential may be reduced with time allotments for group discussions and application exercises during didactic sessions, in addition to the required completion of capstone research projects. Moving forward, teams developing educational opportunities, such as our described HDSE track, should 
investigate the best ways to optimize programing toward maximizing appropriate information transmission and knowledge retention.

Rather than underestimate the commitment required to obtain a basic level of HDSE knowledge, we identified a need among practicing physicians for this training and investigated physicians' interest in one possible introductory HDSE training framework. Additional qualitative research among a population of physicians with significant prior HDSE experiences, such as is available in graduates of Chandran's group, would be most useful.

\section{Disclosure}

The authors report no conflicts of interest in this communication.

\section{Reference}

1. Weeks K, Swanson M, Hansen H, et al. An unmet need in healthcare leadership: a survey of practicing physicians' perspectives on healthcare delivery science education. $J$ Healthcare Leadership. 2020;12:95-102. doi:10.2147/JHL.S265377

Dove Medical Press encourages responsible, free and frank academic debate. The content of the Advances in Medical Education and Practice 'letters to the editor' section does not necessarily represent the views of Dove Medical Press, its officers, agents, employees, related entities or the Advances in Medical Education and Practice editors. While all reasonable steps have been taken to confirm the content of each letter, Dove Medical Press accepts no liability in respect of the content of any letter, nor is it responsible for the content and accuracy of any letter to the editor.

\section{Publish your work in this journal}

Advances in Medical Education and Practice is an international, peerreviewed, open access journal that aims to present and publish research on Medical Education covering medical, dental, nursing and allied health care professional education. The journal covers undergraduate education, postgraduate training and continuing medical education including emerging trends and innovative models linking education, research, and health care services. The manuscript management system is completely online and includes a very quick and fair peer-review system. Visit http://www.dovepress.com/testimonials.php to read real quotes from published authors. 